\title{
Methodical approach to the choice of the variant of the shipbuilding company restructuring
}

\author{
Ganna Iefimova ${ }^{1 *}$, Andrei Labartkava ${ }^{1}$, and Oleksiy Pashchenko ${ }^{1}$ \\ ${ }^{1}$ Admiral Makarov National University of Shipbuilding, 9 Geroiv Ukrainy Ave., 54007 Mykolaiv, \\ Ukraine
}

\begin{abstract}
The issues of the resources use optimizing aimed at a shipbuilding company restructuring are considered, which is the main prerequisite for its effectiveness. The aim of this study is to develop a methodical approach to substantiation of the of the variant of the shipbuilding company restructuring on the basis of optimization-simulation model of its value estimation, which will take into account the algorithmically set conditions regarding the financing scheme, the type of restructuring, technological and economic relations in the system. The task of deciding on the shipbuilding company restructuring and the choice of a specific restructuring project refers to the optimization tasks of long-term planning. The limitations of the mathematical model are the company resources, which are allocated for restructuring. The main optimization criteria are maximizing net present value or minimizing the restructuring cost. The generated optimization model is designed to assess the amount of attracting for restructuring own and borrowed funds. Simulation model provides the cash flows construction. Restrictions on ensuring financial realization reflects the cash flow balance for all activities. The problem solution is achieved on the basis of an interrelated optimization, simulation models and procedures set for the formation, selection and approval of management decisions.
\end{abstract}

\section{Introduction}

The main task of the shipbuilding company restructuring managing in Ukraine, which are in a state of deep crisis or stagnation, is to ensure the position of the shipbuilding company in the market, at which will be overcoming the negative impact of macroeconomic factors and solving internal problems (including financial) by using all modern management capabilities, development and practical implementation of a special program of restructuring measures, which will be strategic.

\footnotetext{
* Corresponding author: hanna.yefimova@,nuos.edu.ua
} 
Company restructuring is a process of complex and interconnected change in the structure of assets, liabilities, company functions, which is initiated by a dynamic environment, based on the strategic concept of its development and aimed at improving the efficiency of its activities, expressed in increasing value [1]. The researches devoted to problems of the shipbuilding companies organizational and economic mechanism adaptation to modern conditions have found the reflection in works [2-6]. However, part of the problem of ensuring the shipbuilding restructuring programs effectiveness remains unresolved.

In our opinion, to ensure the restructuring effectiveness in modern conditions is impossible without the use in the planning process methods and tools of optimization modeling and scenario approach. The complexity of the problem is due to the need the restructuring process modeling based on a significant amount of information and taking into account many factors.

The aim of this study is to develop a methodical approach to substantiation of the of the variant of the shipbuilding company restructuring on the basis of optimization-simulation model of its value estimation, which will take into account the algorithmically set conditions regarding the financing scheme, the type of restructuring, technological and economic relations in the system.

\section{Optimization model of the shipbuilding company value estimating in the restructuring process}

The problem of the shipbuilding company restructuring desicion and its effectiveness estimation is one of the optimization tasks of long-term planning. If we consider it as a mathematical problem, it involves a large number of different procedures with the subsequent choice of all alternatives to the best solution for a set of parameters. The limitations of the mathematical model will be the company resources limitations allocated for restructuring, expressed by a system of equations. The main optimization criterias will be the net present value maximizing or the restructuring cost minimizing.

The first stage is the formation of restructuring alternatives, each of which is determined by the net present value, the amount of own and borrowed funds required for financing. The problem is to choose one option (among which the refusal to restructure). When there are too many alternatives, the dimension of the task increases significantly, which requires preordered selection and reduction of the alternatives number.

The next step is to choose one restructuring variant. To do this, the task is formalized as follows: it is necessary to find the values of variables $Z_{i}, A_{i}(t), K^{+}{ }_{i}(t), K_{i}(t), P_{i}$, which provide the extremum of the selected criterion $F\left(P V_{i}, P_{i}, C M_{i}\right) \rightarrow$ extr under the conditions of execution of analytically and algorithmically set restrictions and conditions. Here:

$Z_{i} \in\{0,1\}, Z_{i}=1$, when the $i$-th restructuring variant is considered, $Z_{i}=0$ in other cases;

$A_{i}(t)$ - own funds of the restructuring company;

$K_{i}^{+}(t) \& K_{i}(t)$ - attraction and repayment amounts of borrowed funds in the restructuring process;

$P_{i}$ - market value of the restructuring company;

$C M_{i}-$ restructuring costs;

$i=\overline{0, I}-$ restructuring variant index $(0-$ corresponds to the variant without restructuring).

Net present value of the company after the restructuring $\left(P V_{i}\right)$ :

$$
P V_{i}=\sum_{t=1}^{T} \frac{C F_{t}}{(1+E)^{t}}
$$

here $C F_{t}$ - cash flow element, which is determined using values $A_{i}(t), K_{i}^{+}(t) \& K_{i}(t)$; $t=\overline{1, T}$ - planning horizon of the company; $E$ - discount rate. 
The difference between the company income after restructuring and the income without restructuring can act as a functional $F\left(^{\circ}\right)$ :

$$
\sum_{i=1}^{I}\left(\left[P V_{i}+P_{i}-C M_{i}\right]-P V_{0}\right) \cdot Z_{i} \rightarrow \max
$$

Or a functional $F\left(^{\circ}\right)$ may be an indicator that minimizes the restructuring cost:

$$
\sum_{i=1}^{I}\left(C M_{i}-P_{i}\right) \cdot Z_{i} \rightarrow \min
$$

Analytically set conditions and constraints are essentially limited opportunities of company restructuring financing:

$$
\sum_{i=1}^{I} A_{i}(t) \cdot Z_{i} \leq S
$$

here $S$ - the maximum amount of shipbuilding company equity that can be used for restructuring measures financing.

The cost of capital is used as a discount rate, which reflects the rate of return of the shipbuilding company in the restructuring process. The discount rate is formed taking into account external and internal factors. Part of them - external - do not depend of the company and reflect the general economic conditions (inflation, general economic risk of the country, regional risk, etc.). The rest - internal - depend on the company and take into account its degree of risk (require careful analysis to avoid double counting).

The conditions and constraints of the model, given algorithmically, include:

- condition for ensuring financial realization:

$$
\sum_{i=1}^{I} \sum_{t=1}^{T} C F_{i}\left(R_{i}(t)-C_{i}(t), K_{i}^{-}(t), K_{i}^{+}(t), A_{i}(t)\right) \cdot Z_{i}>0
$$

here $\left(R_{i}(t)-C_{i}(t)\right)$ - the balance of shipbuilding company flows during the restructuring;

$R_{i}(t)$ - company revenue during the period $t$;

$C_{i}(t)$ - company costs during the period $t$.

The balance of flows from operating, investing and financing activities for period $t$ can be represented as an expression:

$$
\sum_{i=1}^{I} \sum_{t=1}^{T}\left(R_{i}(t)-C_{i}(t)+f_{1}\left(^{\circ}\right)-f_{2}\left(^{\circ}\right)+A_{i}(t)+K_{i}^{+}(t)-K_{i}^{-}(t)-f_{0}\left({ }^{\circ}\right)\right) \cdot Z_{i}(6)
$$

It includes all algorithmically specified functions on the peculiarities of accounting for borrowed funds:

1) $f_{0}\left(p_{n}, p, D, K_{i}^{+}(t)\right)$ - interest function for loans,

here $p$-interest rate on loans;

$p_{n}$ - income tax rate (for companies in the general system of taxation);

$D$ - the amount of borrowed funds raised for restructuring;

2) $f_{1}\left(p_{n}, f_{0}\left({ }^{\circ}\right)\right)$ - capitalized interest depreciation function;

3) $f_{2}\left(p_{n}, \lambda, A m_{i}(t)\right)$ - land tax function,

here $\lambda$ - land tax rate;

$A m_{i}(t)$ - the residual value of capitalized interest in the period $t$.

4) $g D\left(K_{i}^{+}(t), D, K_{i}^{-}(t)\right)$ - requirements for compliance with the conditions of attraction, repayment and servicing of borrowed funds,

here $D$ - debt function, which is determined by the scheme of attraction, repaying and servicing borrowed funds;

$g D$ - a set of requirements for the implementation of the restructuring financing scheme (consistency of attraction, repayment and servicing of borrowed funds, including requirements that depend on the completion date of the program, the limit conditions of the debt amount).

To take into account the residual value of the shipbuilding company, the income to be received in the post-forecast period, one of the following methods is used: Gordon's model, the method of the net assets value calculating, the method of the liquidation value calculating. The method choice depends on which scenario the restructuring and further development of the company will take place.

Given the residual value, the functionality of the optimization model will look like this:

$$
\sum_{i=1}^{I}\left(\left[P V_{i}+P_{i}-C M_{i}+R C_{i}\right]-\left(P V_{0}+R C_{0}\right)\right) \cdot Z_{i} \rightarrow \max
$$


$R C$ - the residual value of the shipbuilding company after the end of the planning period.

In practice the solving of the problem of choosing a shipbuilding company restructuring variant based on the formed optimization model with variables that reflect financial flows, the fact of restructuring, technological and economic links in the system, is quite difficult. The main difficulties are the presence in the model algorithmically given conditions, which cannot be described by analytical functions. The problem solution in this case can be obtained on the basis of an interconnected optimization, simulation models and procedures set for the formation, selection and coordination of management decisions.

\section{Algorithm for selecting a shipbuilding company restructuring variant}

Given the optimization problem complexity, it is advisable to develop an algorithm for its solution, which will present all stages of the decision-making procedure for restructuring and its effectiveness determine. The algorithm for solving the optimization problem of choosing the shipbuilding company restructuring variant on the basis of cost estimation is presented in fig. 1.

The formed optimization model is intended for an estimation of own and borrowed funds attraction amounts for restructuring carrying out. It includes a set of criteria and analytical specified conditions and restrictions. Variables are: Boolean variable $Z_{i}$; continuous variables $A_{i}(t)$ (the own funds amount), $K_{i}^{+}(t) \& K_{i}(t)$ (attraction and repayment amounts of borrowed funds in the process of restructuring). At the same time, there are restrictions on ensuring financial realization, which reflects the cash flow balance for all activities, which connects the optimization model with the simulation model.

The simulation model provides the cash flows construction. It is designed to analyze the financial realization of the restructuring variant, the formation of its financing detailed scheme (the dynamics of borrowing, repayment and servicing of borrowed funds, taking into account the availability of their own assets and reinvestment opportunities). Selection of external financing schemes carries out iteratively (at each step the scheme is specified, interest coverage and debt repayment is provided, that is the condition of financial realization).

Iterations continue until the condition of financial realization is fulfilled or the need to reject this restructuring variant is not established.

Consistency of the company structural and functional elements functioning provides emergence of effects from change, addition or removal of one «element ». The effects can be both positive and negative. To achieve positive effects in the chosen restructuring variant, it is necessary to restore possible broken chains of production or financial processes. In addition, a synergistic effect is possible in the case of the restructuring program formation, which involves the simultaneous change of several elements.

In this case, with a large number of considered variants, the optimization task dimension increases. To solve the problem of large dimension, it is proposed to use special methods that allow organizing a directed search of many variants, which can significantly reduce the number of steps in the complete search algorithms of all combinations. Algorithms based on directional search and dynamic programming method have been developed for some cases. 


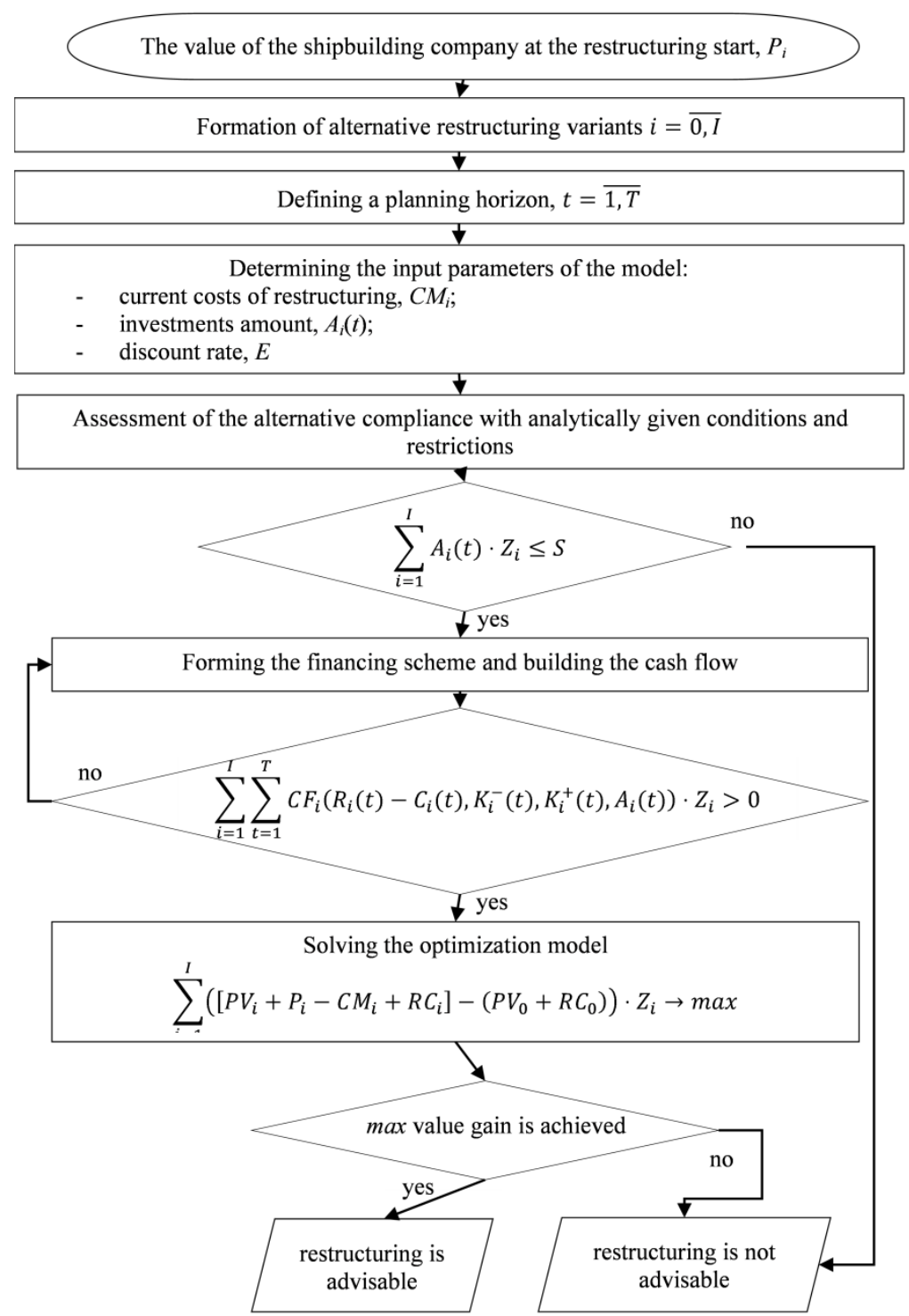

Fig. 1. Algorithm of the restructuring variant selection based on the company valuation.

\section{Approaches to solving the optimization model}

The task solution begins with the consideration of the maximum elements in each row of the matrix $|\mathrm{PVi}|$ and condition checks (5) for the corresponding elements of the coefficient matrix $|\mathrm{Ai}(\mathrm{t})|$. If condition (5) is satisfied, then the vector of maximal elements will be the optimal solution.

The directed search algorithm in application to the task without consideration of restriction (4) consists in movement on the tree vertices received by fixing of a part of variables $\mathrm{Zi}, \mathrm{Zi} \in\{0,1\}$. The first level vertices are obtained by fixing in turn the elements of the system matrix first row (2), the second level vertices - fixing in turn the elements of the system matrix second row (2) etc. 
For the each tree vertex we find the value of the fixed matrix element $|\mathrm{PVi}|$ the objective function evaluation:

$$
\sum_{i<i^{*}} P V_{i}+\sum_{i \geq i^{*}} \overline{P V}_{i}
$$

here $i^{*}$ - branching level; $\overline{P V}_{i}$ - the maximum element in the row.

Branching continues from the level top that has the maximum value of the criterion evaluation and satisfies the constraints.

The sequential search can be reduced, given the restrictions (4): from coefficients matrix $|\mathrm{PVi}| \&|\mathrm{Ai}(\mathrm{t})|$ exclude elements that cannot be included in any valid solution. For each matrix element $|\mathrm{Ai}(\mathrm{t})|$ this condition is checked:

$$
\sum_{i=1}^{m-1} \overline{A_{i}(t)}+A_{m}(t)+\sum_{i=m+1}^{I} \overline{A_{i}(t)} \leq S, m=\overline{1, I}
$$

here $\overline{A_{i}(t)}-$ the minimum element in the row.

Taking into account the limitation (5) allows the application of the described method by introducing a sequential procedure, consisting in a directional motion along the tree vertices obtained from the matrix (2), in which one of the rows is deleted corresponding to removal of a variant from group. It is expedient to compare the received admissible decisions on the qualitative characteristics corresponding to specificity of a task and to choose the optimum decision.

Dynamic programming is an approach that allows you to get the optimal solution to this problem by moving in the opposite direction - from the end of the task to the beginning [7, 8]. The large dimension problem is replaced by a series of smaller dimension problems. The basic recurrent ratio of the task dynamic programming reflects the fact that the maximum value PV, it is necessary to go from step $i$ to the end of the task. This can be obtained by maximizing the sum of the PV values of step $i$ and the maximum PV values that are needed to get from step $\mathrm{i}+1$ to the problem end.

To apply, build a coordinate system on the plane, one axis of which reflects the restructuring elements, and the other discounted cash flows from the implementation of these restructuring program elements. Any path in the network from the initial vertex corresponds to some set of restructuring program elements. If we take the inclined arcs lengths equal to the PV value of the restructuring program variants, and the horizontal arcs lengths corresponding to the "remote" elements equal to zero, the path length connecting the initial vertex with one of the end will be equal to the total PV value corresponding to this path of the restructuring program variant. To take into account the constraint (5), the first program variant is built by drawing a horizontal arc from the origin to 1 on the elements axis that correspond to the first element removal, then build inclined arcs that correspond to the other elements development. In the second variant of the program, the horizontal arcs will correspond to the second element removal and so on. The maximum length path in each set of elements will correspond to the restructuring program variant that gives the maximum value $\mathrm{PV}$, and the best version of the program is obtained by fixing the required amount of allocated funds $\mathrm{S}$. The decision to choose the shipbuilding company restructuring program is made on the basis of maximizing PV.

\section{The algorithm application for the shipbuilding company restructuring variant selection}

Consider the task of optimization on the example of PJSC "Mykolayiv Shipyard "Ocean", where it is planned to implement a restructuring program that includes the following elements:

- production restructuring (restoration of a shipway thread and additional laying of one more, creation of additional place for placement of two more hull blocks);

- organizational restructuring (management structure change, staff reduction); 
- capital restructuring (repayment of wages arrears by financing of received orders, obtaining a loan for modernization).

The main factor indicators of cash flow formation under the restructuring program of PJSC "Mykolayiv Shipyard "Ocean" are given in the table 1.

Table 1. Forecast of cash flow formation factor indicators and value of PJSC "Mykolayiv

Shipyard "Ocean" for different versions of the restructuring program (thousand UAH)

\begin{tabular}{|c|c|c|c|c|c|c|}
\hline Indicator & 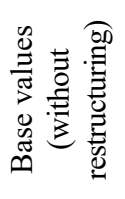 & 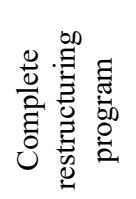 & 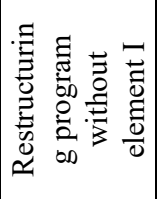 & 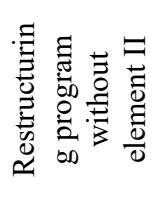 & 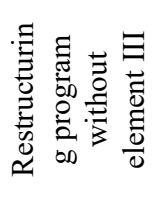 & 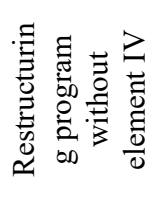 \\
\hline $\begin{array}{l}\text { 1. Own funds } \\
\text { of the company }\end{array}$ & 156203 & 429703 & 429703 & 429703 & 429703 & 429703 \\
\hline $\begin{array}{l}\text { 2. The amount } \\
\text { of own funds } \\
\text { for } \\
\text { restructuring }\end{array}$ & - & 161513 & 132318 & 147516 & 161513 & 150116 \\
\hline $\begin{array}{l}\text { 3. The amount } \\
\text { of borrowed } \\
\text { funds }\end{array}$ & 73541 & 101479 & 84435 & 79223 & 101479 & 112841 \\
\hline $\begin{array}{l}\text { 4. Discounted } \\
\text { restructuring } \\
\text { income }\end{array}$ & 900188 & 1783593 & 1709748 & 1716418 & 1783593 & 1783593 \\
\hline $\begin{array}{l}\text { 5. Discounted } \\
\text { restructuring } \\
\text { costs }\end{array}$ & 447844 & 476465 & 475502 & 479461 & 483031 & 476465 \\
\hline $\begin{array}{l}\text { 6. Company } \\
\text { value }\end{array}$ & 378803 & 1205649 & 1149811 & 1157734 & 1199083 & 1194287 \\
\hline
\end{tabular}

The task consists in a choice of the restructuring program variant of PJSC "Mykolayiv Shipyard "Ocean" by criterion of the company capital value maximization at restriction on the general financing and taking into account restriction (4).

Compare the restructuring program variants of the PJSC "Mykolayiv Shipyard "Ocean" according to table. 1 corresponding to complete the program and its elements successively removal:

$$
\begin{gathered}
P V=1205649 \text { (thousand UAH) } \\
P V_{21}+P V_{31}+P V_{41}=1149811 \text { (thousand UAH) } \\
P V_{12}+P V_{13}+P V_{14}=1157734 \text { (thousand UAH) } \\
P V_{13}+P V_{23}+P V_{24}=1199083 \text { (thousand UAH) } \\
P V_{14}+P V_{24}+P V_{34}=1194287 \text { (thousand UAH) }
\end{gathered}
$$

By limiting the financing possibility (5) and according to the company value maximizing criterion (2) we come to the conclusion about the choice of the fourth variant.

The method of dynamic programming in application to this task can be represented as a matrix method of calculation, convenient for comparison with the dichotomous programming method [9]. Indeed, both the objective function and the functions describing the problem constraints have the same network representation structures, in this case the dichotomous.

In a dichotomous representation, the task corresponding to the vertices of the network representation is the problem of optimizing the two variables function and in the discrete case is solved on the basis of a matrix representation. The first matrix corresponds to the 
second layer of the network. In the upper half of each cell indicates the amount of costs for different variants of the first two elements, and in the lower - the corresponding value PV. It is assumed that the variant to delete a program element is denoted by zeros in both halves of the cell. The second matrix corresponds to the third layer and so on. If there are several cells in the matrix with the same costs, then the next matrix for this cost value is taken the maximum value PV. This corresponds to the principle of Bellman's optimality for the matrix representation of the dynamic programming method. The last matrix (column) takes the optimal values of the total PV of the program variant, consisting of i- 1 elements, with own funds restrictions.

Despite the fact that the general problem solution is a valid variant that optimizes the objective function value, owners are often not satisfied with one optimal variant. In most cases, it is necessary to know what optimization is achieved, and if the "losses" on other indicators are large, then also consider variants for a restructuring program, close enough to the optimal. The problem decision of a choice of the shipbuilding company restructuring program at the following stages consists in a choice of the most attractive variant from their set based on the criteria.

\section{Conclusions}

The optimization models use to select a restructuring variant for a shipbuilding company allows to determine the best alternative given the existing limitations. However, in its pure form, the optimization models use to decide on the restructuring is quite difficult given that not all parameters and conditions can be described by analytical functions. In this case, it is best to use optimization models in conjunction with simulations models. This will make the shipbuilding restructuring planning process dynamic, i.e. will allow to take into account algorithmically set conditions and will significantly increase the accuracy of the decision to choose the most effective option for shipbuilding restructuring.

\section{References}

1. Iefimova, Ganna V. (2014) Optimization modeling of shipbuilding enterprise restructuring efficiency. Business Inform, 3,109-113. https://www.businessinform.net/export pdf/business-inform-2014-3 0-pages-109_113.pdf -

2. Iefimova, Ganna V., \& Labartkava, Andriy V. (2015) Integration as a strategy for restructuring shipbuilding enterprises. Modern management: problems, hypotheses, researches: proceeding of material. Batumi, 45-48.

3. Iefimova, Ganna V., \& Rogov, Viycheslav G. (2019) Adaptation of the shipbuilding enterprise to changes in the incentives for its development. Management and Entrepreneurship in Ukraine: Stages of Formation and Problems of Development, 1(1), 92-105. https://doi.org/10.23939/smeu2019.01.092 -

4. Burkinskyi, B. V., Laiko, O., \& Losyev, M. (2018) Realization of sustainable development aims for industry and innovations on glocalization principles. Economic innovations, 20 (4 (69)), 7-22. https://doi.org/10.31520/ei.2018.20.4(69).7-22

5. Imbalances in the shipbuilding industry and assessment of policy responses. (2017) https://www.oecd.org/industry/ind/Imbalances Shipbuilding Industry.pdf

6. Solli-Sæther, Hans \& Karlsen, Jan. (2012) Knowledge transfer in shipbuilding projects: A study of supporting mechanisms. International Journal of Project $\begin{array}{llll}\text { Organisation } \quad \text { and } & \text { Management, } & \text { 256-271. }\end{array}$ https://dx.doi.org/10.1504/IJPOM.2012.048224 
7. Grebennik I. V., Chernaia O.S.,\& Makarova E.E. (2018) Optimization of linear functions on the set of cyclic permutations with linear constraints. Control, navigation and communication systems, 3(49), 67-72 https://doi.org/10.26906/SUNZ.2018.3.067

8. Martine van den Boomen, Pieter L. van den Berg \& A. Rogier M. Wolfert (2019) A dynamic programming approach for economic optimisation of lifetime-extending maintenance, renovation, and replacement of public infrastructure assets under differential inflation. Structure and Infrastructure Engineering, 15(2), 193-205 https://doi.org/10.1080/15732479.2018.1504803

9. Burkov V., Shchepkin, A., Irikov, V., \& Kondratiev V. (2019) Methodology and Technology of Control Systems Development. In: Kravets A. (eds) Big Data-driven World: Legislation Issues and Control Technologies. Studies in Systems, Decision and Control, vol 181. Springer, Cham. https://doi.org/10.1007/978-3-030-01358-5_2 